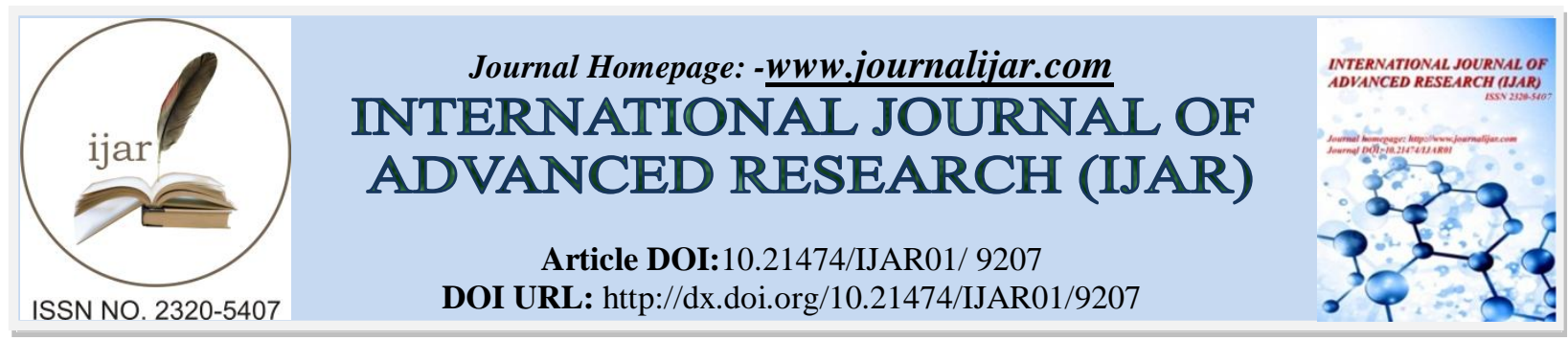

RESEARCH ARTICLE

\title{
PRIMARY BREAST LYMPHOMA: REPORT OF 2 CASES AND REVIEW OF THE LITERATURE.
}

\author{
Murad V. ${ }^{1}$, Torres DF. ${ }^{2}$, Viveros $\mathrm{JM}^{3}$ and Bedoya $\mathrm{ND}^{4}$. \\ 1. Vanessa Murad G. Radiologist. Hospital Universitario Fundación Santa Fe de Bogotá. \\ 2. David Fernando Torres Cortes. Radiology resident. Hospital Universitario Fundación Santa Fe de Bogotá. \\ 3. Juan Manuel Viveros. Radiologist. Universidad Nacional de Colombia. \\ 4. Nelson David Bedoya. Radiologist. Hospital Universitario Fundación Santa Fe de Bogotá.
}

\section{Manuscript Info}

\section{Manuscript History}

Received: 04 April 2019

Final Accepted: 06 May 2019

Published: June 2019

Key words:-

Breast, lymphoma, images, radiology. non-Hodgkin's.

\begin{abstract}
Primary breast lymphoma (PBL) is a very rare disease. Most breast lymphomas (70-90\%) are non-Hodgkin's type (NHLs), and diffuse large B-cell (DLBCL) account for 56\% - 84\%. They mainly affect women between 55 and 62 years, but they can also affect men. Clinically they present as painless, fast growing masses and there are four main criteria for the diagnosis of primary breast lymphoma. Imaging features are non-specific, although there are the key to suspect it. Diagnosis is confirmed with core needle or excisional biopsy and immunohistochemistry. We present two representative cases of PBL from our institution and a complete review of the literature.
\end{abstract}

Copy Right, IJAR, 2019,. All rights reserved.

\section{Introduction:-}

\section{Case 1}

71-y.o female with a painful palpable rapid growing mass in her right breast. She has family history of breast cancer in 3 aunts. In her prior control, 2 years ago, she was asymptomatic and had a BI-RADS 2 mammogram. Physical examination demonstrates a $18 \mathrm{~mm}$ non-mobile indurated mass, attached to the skin but without retraction, and a free axilla. Mammogram, ultrasound and ultrasound guided core biopsy were performed and the final diagnosis was a diffuse large B-cell lymphoma (Figure 1, Figure 2, Figure 3).

\section{Case 2}

34-y.o female with a new palpable solid mass in her right breast. She has no relevant previous history. At physical examination a 4,5 $\times 3 \mathrm{~cm}$ solid mass was noted in the upper external quadrant of the right breast with one mobile axillary node. Study of the lesion was completed and final pathology report showed a high-grade B-cell lymphoma (Figure 4, Figure 5).

\section{Literature review}

Primary breast lymphoma is a very rare disease due to the small amount of lymphoid tissue in the breast, accounting for $0.04 \%$ to $0.74 \%$ of all breast malignancies. Most breast lymphomas (70-90\%) are non-Hodgkin's type (NHLs), representing $0.7 \%$ to $2 \%$ of extra nodal NHLs $(1,2)$.

They mainly affect women (98\%-100\%) in a broad range of age from 15 to 95 years, with a median age of 55 - 62 years; nevertheless there are few cases in younger women (as in case 2) and in men reported in the literature $(2,3)$. 
These neoplasms can arise from lymphatic tissue adjacent to ducts and lobules, from intramammary lymph nodes and, least frequently, from mucosa-associated lymphoid tissue (4). Most breast lymphomas are diffuse large B-cell (DLBCL) which account for $56 \%$ to $84 \%$ as in our cases, followed by marginal zone lymphoma (9-28\%), follicular lymphoma (10-19\%) and Burkitt lymphoma $(<5 \%)(3,4,5)$. In women with breast implants there is a higher incidence of anaplastic large cell lymphoma (ALCL), which ranges between $0.1-0.3$ per 100.000 cases (6).

They are usually unilateral and most commonly located in the right upper quadrant, even though 1-14\% may be bilateral, specially associated with pregnancy and lactation (2).

There are no determined risk factors, but a number of case series have reported a higher prevalence in women with estrogen hormone replacement therapy and autoimmune diseases as Hashimoto's thyroiditis (3); none of our patients had risk factors.

Clinically they present as painless palpable masses, which tend to be large in size and to grow fast, as in our cases. Constitutional symptoms and cutaneous manifestations are very rare and in $12 \%$ of cases they are found incidentally (7). Diagnosis is confirmed with core or excisional biopsy and immunohistochemistry $(2,4)$.

According to the International Extranodal Lymphoma Study Group there are four main criteria for the diagnosis of primary breast lymphoma: 1) tumor is within the breast, 2) no history of previous lymphoma, 3) histological demonstration of close association between lymphoma and breast tissue, and 4) ipsilateral lymph nodes may be involved simultaneously with the primary tumor. This criteria show that only tumors in stages I (limited to the breast) and II (limited to breast and ipsilateral nodes) are considered primary (4).

Imaging features are non-specific. At mammography the most common appearance is a well-circumscribed large and hyperdense mass without calcifications or desmoplastic reaction (spiculation and architectural distortion). Other rare presenting patterns include multiple irregular masses, increased parenchymal density, skin thickening and milliary densities $(1,8)$. Suspicious intramammary nodes characterized by enlargement, lost of their margins and increased density with loss of the fatty hilium should raise concern (8). Ultrasound may show well-circumscribed and hypoechoic lesions with the same patterns.

At MRI masses are solid, circumscribed, without desmoplastic reaction, showing high or mild heterogeneous internal enhancemen $(9,10)$. Recent nuclear medicine techniques such as PET/MRI can show high 18F-FDG uptake in multinodular enhancing masses and have the advantage of accurately determine the extension of the disease (5).

Differential diagnoses include primary breast cancer, phyllodes tumor, fibroadenoma and metastatic disease $(11,12)$.

Treatment includes radiation therapy, chemotherapy and surgery, which in combination ensure a better prognosis $(13,14)$.
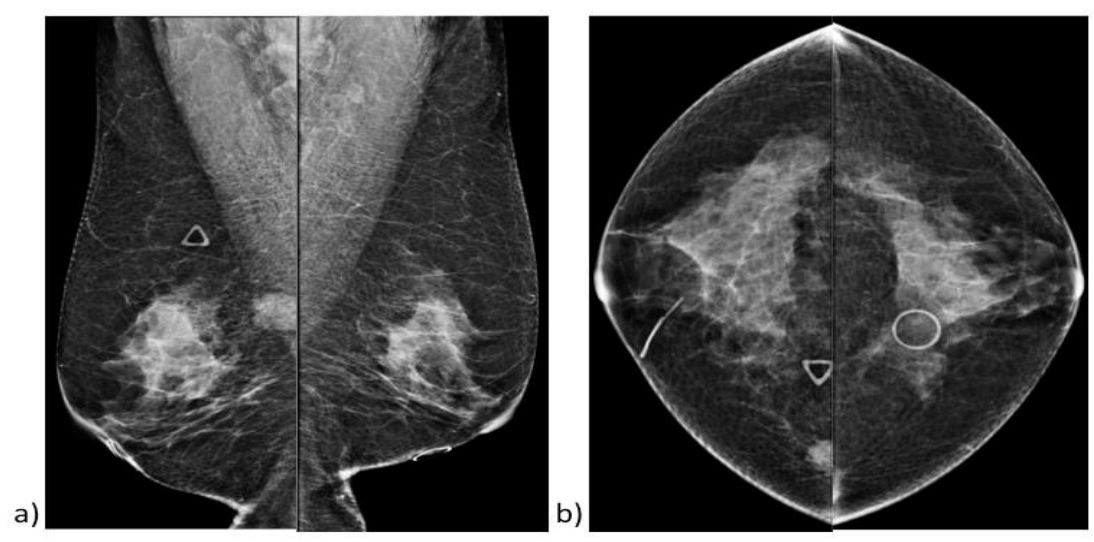

Figure 4:-Digital mammography: a) MLO view and b) CC view. In the right breast, deep retroareolar region, there is an oval, circumscribed, isodense mass with a diameter of $18 \mathrm{~mm}$, which was not evident on the previous study. BIRADS 4B. 
a)
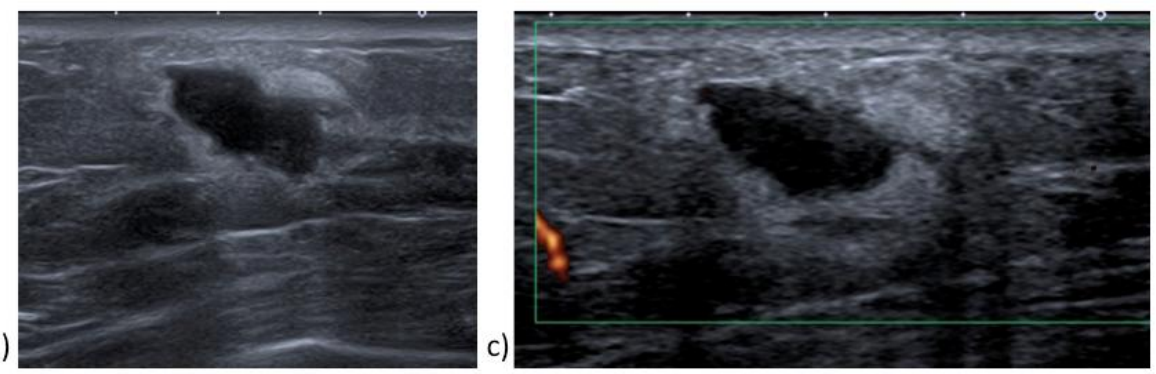

b)

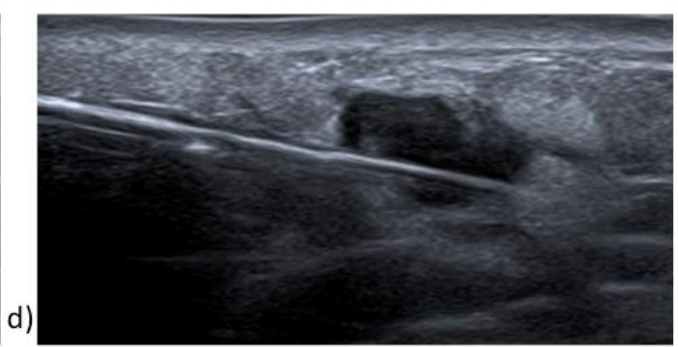

Figure 5:-Breast Ultrasound $(\mathrm{a}, \mathrm{b}, \mathrm{c})$. In the right breast, same location as mammogram, there is an irregular lobulated mass, with cystic and solid components with incomplete echogenic halo. Mass dimensions: $17.8 \mathrm{x} 8.5 \mathrm{x}$ $15.2 \mathrm{~mm}$. The nodule presented discrete vascularization in the periphery. c) Biopsy was performed and the final diagnosis was a diffuse large B-cell lymphoma.

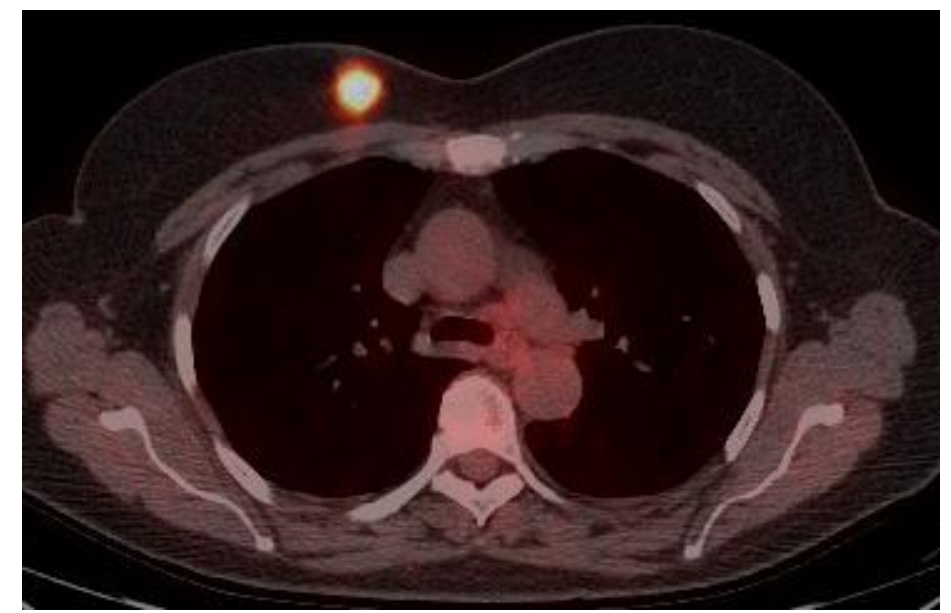

Figure 6:-PET/CT shows the hypermetabolic focal lesion in the right breast consistent with malignancy.

a)
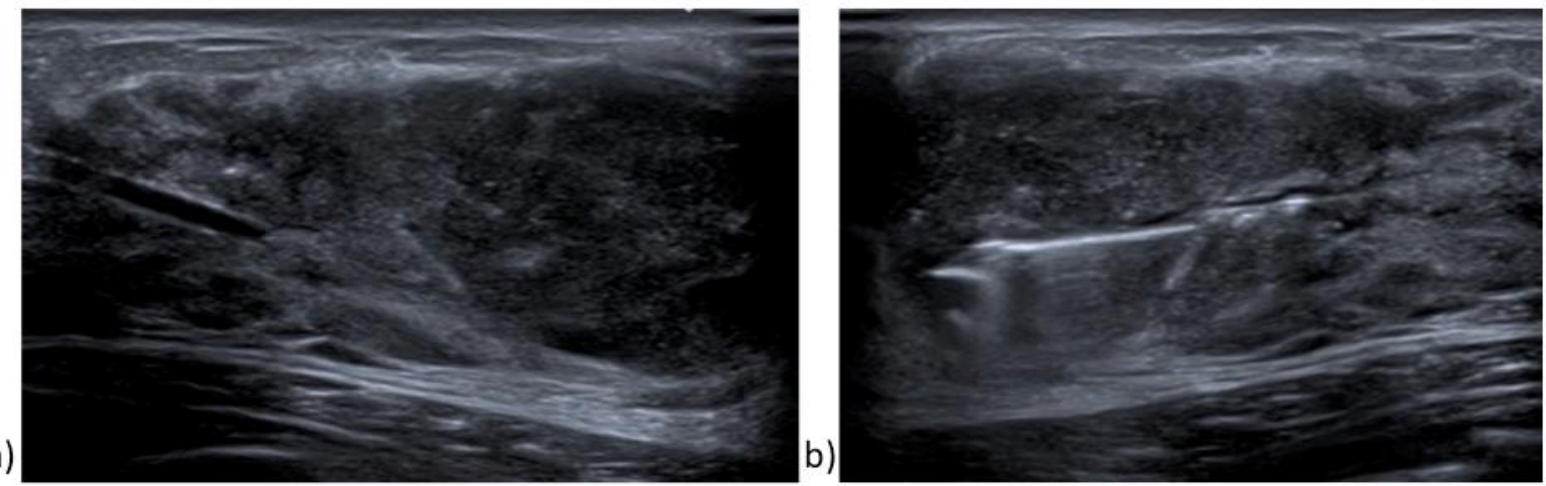

Figure 7:-a) Breast ultrasound showing an heterogeneous echogenicity solid mass of 30 x $21 \mathrm{~mm}$, located in the periareolar región at $10 \mathrm{~mm}$ from the nipple of the right breast. b) Biopsy was performed and the final diagnosis was a high grade B-cell lymphoma. 


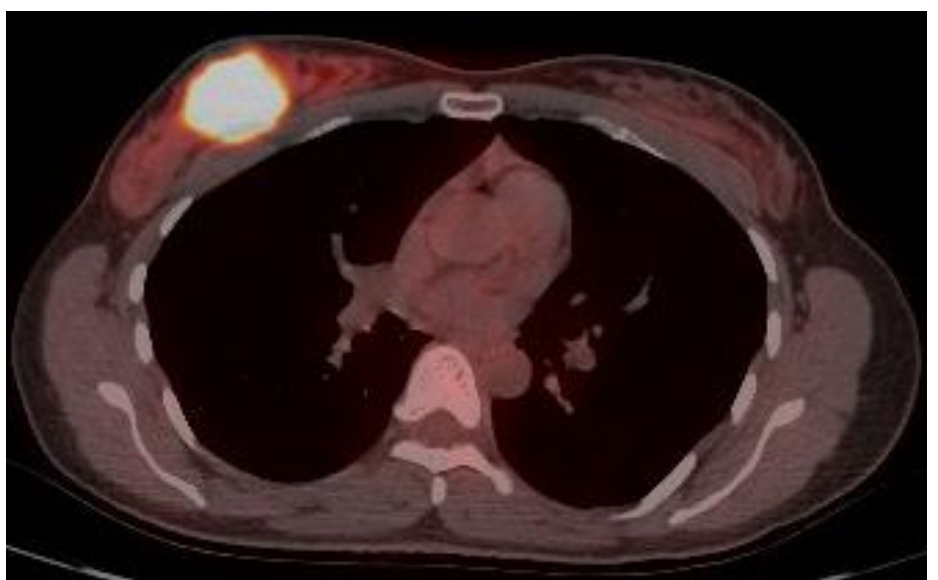

Figure 8:-PET/CT shows the hypermetabolic focal lesion in the right breast consistent with malignancy.

\section{References:-}

1. Of O. Hodgkin 's Lymphoma of the Breast. 2010;28(2):2009-11.

2. Yang H, Lang R, Fu L. Primary breast lymphoma (PBL): A literature review: (2011) 8: 128-132.

3. Cheah CY, Campbell B a., Seymour JF. Primary breast lymphoma. Cancer Treat Rev. Elsevier Ltd; 2014;40(8):900-8.

4. Joks M, Myśliwiec K, Lewandowski K. Primary breast lymphoma - a review of the literature and report of three cases. Arch Med Sci. 2011;7(1):27-33.

5. Kong EJ, Cho IH. F-18 FDG PET/MRI findings of primary breast lymphoma in two cases. FDG PET/MRI findings of primary breast lymphoma. Clin Imaging. 2015;39(4):682-4.

6. Yang WT, Lane DL, Abruzzo L V, Macapinlac H a. Breast Lymphoma : Imaging Methods : Results : Conclusion : 2007;245(3).

7. Sabaté JM, Gómez a., Torrubia S, Camins a., Roson N, De Las Heras P, et al. Lymphoma of the breast: Clinical and radiologic features with pathologic correlation in 28 patients. Breast J. 2002;8(5):294-304.

8. Zack JR, Trevisan SG, Gupta M. Intramammary Lymph Node. 2001;(July):177-8. 11. Naganawa S, Endo T, Aoyama H, Ichihara S. MR Imaging of the primary breast lymphoma : A case report. 1996;3(3):3-4.

9. Liu K, Xie P, Peng W, Zhou Z. The features of breast lymphoma on MRI. Br J Radiol. 2013;86(1031):1-6. 29. Yang H, Lang R, Fu L. Primary breast lymphoma (PBL): A literature review. Clin Oncol Cancer Res. 2011;8(3):128-32.

10. Mussurakis S, Carleton PJ, Turnbull LW. MR imaging of primary non-Hodgkin's breast lymphoma. A case report. Acta Radiol. 1997;38(1):104-7.

11. Sim E, Song SE, Seo BK, Kim Y, Son GS. Breast Cancer Lymphoma Affecting the Breast : A Pictorial Review of Multimodal Imaging Findings. 2013;16(3):254-65.

12. Surov A, Holzhausen HJ, Wienke a., Schmidt J, Thomssen C, Arnold D, et al. Primary and secondary breast lymphoma: Prevalence, clinical signs and radiological features. Br J Radiol. 2012;85(1014):195-205.

13. Aviv Dr. a., Tadmor T, Polliack a. Primary diffuse large B-cell lymphoma of the breast: Looking at pathogenesis, clinical issues and therapeutic options. Ann Oncol. 2013;24(9):2236-44.

14. Jennings WC, Baker RS, Murray SS, Howard CA, Parker DE, Peabody LF, et al. Primary breast lymphoma: the role of mastectomy and the importance of lymph node status. Ann Surg. 2007;245(5):784-9. 